\title{
Chronic poverty, wars and mental health: the East African perspective
}

\section{Fred Kigozi ${ }^{1}$ and Joshua Ssebunnya ${ }^{2}$}

${ }^{1}$ Executive Director, Butabika National Mental Hospital, Uganda, and Principal Investigator, Mental Health and Poverty Project ${ }^{2}$ Research Officer, Mental Health and Poverty Project, Makerere University/Butabika National Mental Hospital, Uganda

G lobally, poverty has been noted to be a high risk factor for mental disorder. Although there is limited information on the baseline prevalence of mental disorders in low- and middle-income countries, the known risk factors for poor mental health, such as poverty and violence, afflict many of these areas (Miller, 2006). It is clear that poverty and the mental health consequences of war and displacement significantly hinder the achievement of the Millennium Development Goals (Njenga et al, 2006).

East Africa comprises Burundi, Kenya, Rwanda, Tanzania and Uganda. According to the World Bank rankings, all these are low-income countries, where close to half the population lives below the poverty line. East Africa has an estimated population of 130 million and one of the highest population growth rates in the world. The region is, however, grossly underresourced. This is particularly true in relation to human resources for mental health; for example, it has an average of only 0.08 psychiatrists per 100000 population (World Health Organization, 2005).

The most pressing problems in East Africa relate to HIV/ AIDS, extreme poverty and poor governance, as well as equity in the distribution of resources. Poverty is both a cause and consequence of high prevalence rates of AIDS in East Africa (Njenga et al, 2006). Poor governance links to chronic poverty through corruption, lack of infrastructure and lack of opportunities. Moreover, over $40 \%$ of the population live below the poverty line in East Africa, and this proportion is expected to grow (Njenga, 2002).

\section{Poverty and mental health}

Poverty has been described as the biggest enemy of health in low- and middle-income countries. The World Health Report 2001 pointed to the relationship between poverty and mental disorders (World Health Organization, 2001). Countries in Africa are facing a double burden of disease and insufficient resources, with almost $80 \%$ of the continent's countries spending less than $1 \%$ of their health budgets on mental health (Njenga, 2002).

In a situational analysis of the mental health system in Uganda, conducted recently as part of the Mental Health and Poverty Project (Kigozi et al, 2007), most study participants identified poverty as a major risk factor for mental illness. Poverty was reported to be a strong causative and mediating factor for mental health problems such as stress, frustrations, anxiety and depression. According to participants, many poor and unemployed people, especially the uneducated, attempt to cope with their frustrations and social problems by resorting to alcohol and other illicit substances, which make them more susceptible to mental health problems. It also emerged that delayed help-seeking and incomplete treatment dosages are common among poor persons with mental illness, who have access to medication only intermittently and often only to the cheap drugs, which usually have disabling side-effects.

Some of the participants described the relationship as a vicious cycle and maintained that while poverty is a contributory factor for mental illness, poverty can also be a result of mental illness; hence a strong two-way relationship exists. Service users noted that, in addition to people with mental illness being unproductive during the time they are hospitalised or on treatment, carers also spend much time nursing sick relatives. This lowers their productivity, resulting in significant economic decline. One user specifically described the recurrent nature of mental illness as characterised by high expenses and no productive work, often leading to financial loss (Kigozi et al, 2007). It was further reported that people with mental illness sometimes become destructive, leading to strained relationships with family and neighbours, and a need to spend money on the resolution of disputes at local courts. This further encroaches on their meagre resources.

\section{Consequences of wars on mental health}

The East African region has been characterised by war, conflict and genocide over the past three decades. There have been massive internal and external displacements of people due to strife in the region, resulting in a considerable number of internally displaced persons (IDPs) and refugees. It is also home to some of the largest refugee populations in the world, mainly from the neighbouring countries of Ethiopia, the Democratic Republic of Congo, Somalia and southern Sudan. Studies conducted in the region and elsewhere indicate that post-traumatic stress disorder (PTSD), depression, suicide, alcohol and drug use markedly increase in post-war environments (Musisi, 2004).

Wars have a catastrophic effect on the health and wellbeing of nations. Studies have shown that conflict situations cause more mortality and disability than any major disease. The effect on the mental health of the civilian population is among the most significant consequences of war. Studies of the general population in post-conflict situations show an increase in the incidence and prevalence of mental disorders (Srinivasa \& Lakshminarayana, 2006). Conflict situations trigger stress and are usually associated with excessive substance misuse as a coping strategy. 
Several studies have reported the frequency of mental disorders in the war-affected populations of East Africa, the most common ones being PTSD, depression, anxiety, somatisation disorder, and alcohol and substance use disorders (Neuner et al, 2004; Njenga et al, 2006); the reported prevalence of PTSD has ranged between $28 \%$ and $80.2 \%$ of the study populations. The World Health Organization (2001) estimated that, in the context of armed conflict, $10 \%$ of the people who experience traumatic events will have serious mental health problems and another $10 \%$ will develop behaviour that will hinder their ability to function effectively, and thus be unable to contribute significantly to the economic growth of that population. The most common conditions are similar to those reported above.

Northern Uganda, which has seen war for the past two decades, and which has nearly $50 \%$ of its population on the move or categorised as IDPs, has one of the world's highest rates of mental illness. In a study in two northern Uganda districts, more than $54 \%$ of the adults screened had PTSD (Njenga et al, 2006). Furthermore, the physical and mental health problems of the survivors of the genocide in Rwanda have been well documented. In a community-based study examining 2091 people, 24.8\% met the DSM-IV symptom criteria for PTSD (Srinivasa \& Lakshminarayana, 2006).

\section{Conclusions}

Although there is a paucity of local data on poverty and mental ill-health, there is sufficient evidence of a significant association between the two. It is therefore imperative that mental health is given as much weight as any other development issue, so that appropriate programmes can be designed to address the socio-economic challenges resulting from or causing mental disorders. Furthermore, it will be only through a greater understanding of the causes of conflicts that coherent and effective strategies for dealing with the resulting mental health consequences, discussed above, can be developed.

\section{References}

Kigozi, F., Ssebunnya, J., Kizza, D., et al (2007) Situational Analysis of the Mental Health Systems in Uganda (unpublished).

Miller, G. (2006) Mapping mental illness: an uncertain topograph. Science, 311, 460-461.

Musisi, S. (2004) Mass trauma and mental health in Africa. African Health Sciences, 4, 80-82.

Neuner, F., Schauer, M., Karunakara, U., et al (2004) Psychological trauma and evidence for enhanced vulnerability for posttraumatic stress disorder through previous trauma among West Nile refugees. BMC Psychiatry, 4, 34

Njenga, F. G. (2002) Challenges of balanced care in Africa. World Psychiatry, 1, 96-98

Njenga, F. G., Nguithi, A. \& Kang'ethe, R. N. (2006) War and mental disorders in Africa. World Psychiatry, 5, 38-39.

Srinivasa, R. M. \& Lakshminarayana, R. (2006) Mental health consequences of war: a brief review of research findings. World Psychiatry, $5,25-30$.

World Health Organization (2001) World Health Report 2001 - Mental Health: New Understanding, New Hope. WHO

World Health Organization (2005) Mental Health Atlas. WHO.

\title{
Inequity and poverty: everyday emotional disturbances and mental disorders in the Mexican urban population
}

\author{
Shoshana Berenzon, ${ }^{1}$ Maria Asunción Lara ${ }^{1}$ and Maria Elena Medina-Mora ${ }^{2}$
}

\begin{abstract}
${ }^{1}$ Researcher, National Institute of Psychiatry Ramón de la Fuente Muñíz, Mexico ${ }^{2}$ Director of the National Institute of Psychiatry Ramón de la Fuente Muñíz, Mexico
\end{abstract}

\begin{abstract}
ecent decades have seen renewed interest in the study Nof poverty and its repercussions on various health problems, including mental disorder (Patel, 2007). There are various ways of measuring poverty; some approaches define it in economic terms, whereby health is included only as an asset that must be given to those defined as poor (Damián \& Boltvinik, 2003). Other conceptions propose definitions based on the capacity of the poor to improve their standard of living, and consider health and education as essential elements in this process. This is the case of the Human Development Index (HDI), which, in addition to the economic dimension, measures other social indicators such as life expectancy, literacy and school enrolment and drop-out rates, among others (United Nations
\end{abstract}

Development Programme, 2000). On the basis of the HDI, Mexico ranks 52 out of 177 countries. According to its percentage of gross domestic product invested in health, it is regarded as a country with a medium/high income level.

Despite these data, inequity continues to be one of the main problems in Mexico, and indeed in Latin America more widely. The region's population is polarised socioeconomically, and access to opportunities is markedly different for the various social sectors. According to the Economic Commission for Latin America (ECLA, 2008), the region has an extremely unequal income distribution, with the richest $10 \%$ of individuals earning $40-47 \%$ of total income in most Latin American societies, and the poorest $20 \%$ earning just $2-4 \%$. 